\title{
Exploring the Benefits of Integrating Business Model Research within Living Lab Projects
}

\author{
Olivier Rits, Dimitri Schuurman, and Pieter Ballon
}

\author{
"( Luck is a matter of preparation meeting opportunity. ") \\ Lucius Annaeus Seneca (4 BC - AD 65) \\ Writer, philosopher, and statesman
}

\begin{abstract}
Business model and living lab research both have similar objectives - to maximize the probability of successful market introduction of innovative solutions - be it through different means. Yet, there are still only few studies or reports discussing both, with those studies that do touch the subject staying at a high level. iMinds Living Labs has gained a lot of experience in combined living lab and business model innovation projects and, rather than being competing approaches, our results have shown that these two research methodologies can be complementary, where the combined approach turns out to be more powerful than each individual approach used alone. The goal of this article is to promote the inclusion of business model research in a model of "a living lab as a service" (and vice versa) by explaining the benefits and by introducing a practical framework to implement such combined research tracks based on the experience at iMinds Living Labs over the past few years.
\end{abstract}

\section{Introduction}

The definition of a "living lab" is still an unresolved and largely semantic discussion (Baccarne et al., 2013). However, most definitions focus on: i) the collaboration between different stakeholders - including end users during the innovation process and ii) combining technological research with user research. But, even if they recognize the need to involve multiple stakeholders, including business partners, this involvement in most living lab approaches extends no further than collecting some general feedback from a number of business representatives during the ideation or evaluation stage. The explication and validation of the actual business model of the innovation in question is seldom included within a living lab project.

For those studies and reports that do take the business model aspect into account, we can generally categorize them into three different focus areas:

1. The largest group of studies focuses on multi-actor living lab consortia and considers the collaboration model between these partners as a key issue in securing a sustainable and long-term collaboration agreement (Garcia-Guzman et al., 2013; Grezes et al., 2013;
Mulvena et al., 2010; Niitamo et al., 2006; Nikolov \& Antonova, 2012; Pitse-Boshomane et al., 2008; Schaffers et al., 2009). In these studies, the lack of a good business model is considered to be a major possible roadblock to open innovation within living labs. The living labs from these studies do not focus on a "living lab as a service".

2. A smaller group of studies focusses on the business model of the living lab platform itself as a way to become self-sufficient and generate enough revenues from the services provided (Garcia-Guzman et al., 2013; Grezes et al., 2013; Katzy, 2012; Mulvena et al., 2010). These studies discuss what the market needs from living lab platforms, stipulating best practices of the type of assets (resources) and activities (services) a living lab should offer to the market. It is interesting to note that, among these studies, almost none includes business model research as a possible service for living lab actors.

3. Finally, a third group of studies state that a living lab project might provide insights not only on user needs and practices, but also on new business model opportunities (Agerskov et al., 2013; Grezes et al., 2013; Katzy, 2012; Mulvena et al., 2010; Niitamo et al., 2006; 


\section{The Benefits of Integrating Business Model Research within Living Lab Projects}

\section{Olivier Rits, Dimitri Schuurman, and Pieter Ballon}

Nikolov \& Antonova, 2012; Schaffers et al., 2009; Schuurman et al., 2011; Svensson \& Eriksson, 2009). However, after making such general statements, the focus of these studies usually turns entirely back towards the user research part, leaving the business model aspect undefined and providing no practical guidelines whatsoever on how to make the link.

None of the mentioned studies discusses the need to consider the business model of the innovation itself during the living lab project. In terms of the three levels of analysis for living labs (cf. Schuurman, 2015), the business model is only considered on the macro level, whereas only minor attention is dedicated to the business model within a living lab project (meso level) or towards concrete business model support methods and tools (micro level). Svensson and Eriksson (2009) are the only authors that explicitly state the importance of addressing the business model of the innovation itself early on in the process. Interestingly, their study also takes the viewpoint of the small or medium-sized enterprise as point of departure, but unfortunately does not discuss this topic in detail.

In sum, most of the living lab community is considering business models mainly in order to optimize their own operations and sustainability. Moreover, the few studies from the living lab literature that do mention business model services for innovation projects on top of the living lab platform, remain high-level without providing any insights into guidelines or results, or without explicitly explaining the benefits. Within this article, we address this gap by promoting the inclusion of business model research in a "living lab as a service" model (and vice versa). We begin by describing the benefits of a business model research perspective on living labs. Next, we share our experiences using a practical framework to implement combined research tracks at iMinds Living Labs. We conclude by discussing the implications of our contribution and our future research areas.

\section{A Business Model View of Living Labs}

Similar to the situation with living labs, many different definitions have been put forward within the business model literature. Some studies (e.g., Al-Debei \& Avison, 2010; Nenonen \& Storbacka, 2010) even consist of metaanalyses of the different definitions in order to abstract the different elements of the business model construct. Most literature on business models stresses their importance for successful innovation (Magretta, 2002;
Shafer, 2005; Teece, 1986, 2010; Voelperl, 2005; Zott, 2010). Additionally, most business model literature focuses on one or more of the following levels:

1. The framework level: This level defines what a business model is, lists the building blocks that make up the business model, and clarifies the link with strategy. The intention is usually to provide clear guidelines and a comprehensive list of choices involved in business model design (e.g., Cassadesus-Masanell, 2010; Magretta, 2002; Nenonen, 2010; Shafer, 2005; Teece, 2010; Zott, 2010).

2. The analysis level: This level tries to define successful design rules for innovative or successful business models, by describing what works. Compared to the purely descriptive character of the framework level, the analysis level provides clear advice and tools for analysis mostly focusing on the coherency between the choices defined at the framework level (Cassadesus-Masanell, 2010; Giesen, 2007; Magretta, 2002; Teece, 2010; Zott, 2010).

3. The process level: This level stipulates the processes involved in designing or (more often) innovating the business model. This level is the least covered by business model literature and the small literature base is more practitioner-oriented and tackles topics such as when to innovate or change the business model and which triggers or trends to follow (Giesen, 2007; Shafer, 2005; Voelpel, 2005).

From this literature overview, we conclude that there is a lack of studies dealing with an actual iterative process of designing, experimenting with, and redesigning business models. As discussed earlier, living labs involve external actors (e.g., users, consumers, stakeholders, and partners) in a highly iterative lean innovation process to uncover important external contextual factors and validate assumptions about customer behaviour (Schuurman et al., 2013). In that respect, we consider living labs as the perfect vehicle to support business model design at the process level. Popular business model references implicitly support our claim:

- Magretta (2002): “Ultimately, models like this fail because they are built on faulty assumptions about customer behavior."

- Shafer (2005) mentions "flawed assumptions" at different levels in the business model framework as a cause of business model problems. 


\title{
The Benefits of Integrating Business Model Research within Living Lab Projects
}

\author{
Olivier Rits, Dimitri Schuurman, and Pieter Ballon
}

- Voelpel (2005): "Research indicates that the creation of a dramatically new customer value proposition(s) and/or sensing potential breakthrough change in customer behaviour are often the initial driving forces behind sound new business models."

- Casadesus-Masanell (2009) points out that business models do not operate in isolation and have different outcomes and consequences depending on the "context".

- Teece (2010): “A business model is successfully pioneered only after considerable trial and error ... once articulated, it likely will have to be tested and retested, adjusted and tuned as the evidence with respect to provisional assumptions becomes clarified."

- Teece (2010): "What business model pioneers often posses - or develop - is an understanding of some 'deep truth' about the fundamental needs of customers and how competitors are or are not satisfying those needs, and of the technological and organizational possibilities (and trajectories) for improvement."

Unfortunately, most references do not explicitly detail how to deal with these challenges and concepts, and living labs have not been recognized within the business model literature as a powerful approach to support business model research at the process level.

In conclusion, even if both living lab and business model research have similar objectives, and even though at least the business model community recognizes the usefulness of the concepts provided in a living lab approach, we see no structural linking between both research streams. In a way, this is not at all surprising given that both living lab and business model research are still rather young disciplines that both lack clear and broadly accepted definitions. Therefore, within the next section, we will provide some practical guidelines on how to integrate both research tracks based on our own experiences gained within more than 50 projects carried out within iMinds Living Labs.

\section{The iMinds Living Lab Approach}

Over the past three years, the living labs department at the iMinds (iminds.be) digital research and entrepreneurship hub in Flanders, Belgium, has been conducting a series of living lab projects specifically targeted at individual small and medium-sized enterprises (SMEs) (see Schuurman, 2015). Within these more than 50 projects at iMinds Living Labs, the need of SMEs to include business model aspects as part of the living lab exercise gradually came to the forefront.

Before business modeling activities were embedded into the living lab projects, the project outline consisted of an iterative series of user research steps. These steps were meant to support companies in exploring, validating, or testing their innovative solutions with end users (Figure 1).

These innovation projects start with a kick-off meeting during which the living lab researchers, together with the instigator (i.e., the individual or group of individuals from whom the idea or need at the start of the living lab originates, and who enter into the living lab process as clients), log the assumptions about the users and stakeholders and agree on the corresponding research questions.

In a second step, the living lab researchers scan the environment or assess the "state of the art" (SotA). This step aims to obtain a good view of the market from a user perspective and is the basis for the next research steps. Based on the maturity of the innovation and the type of research questions to be answered, a selection is

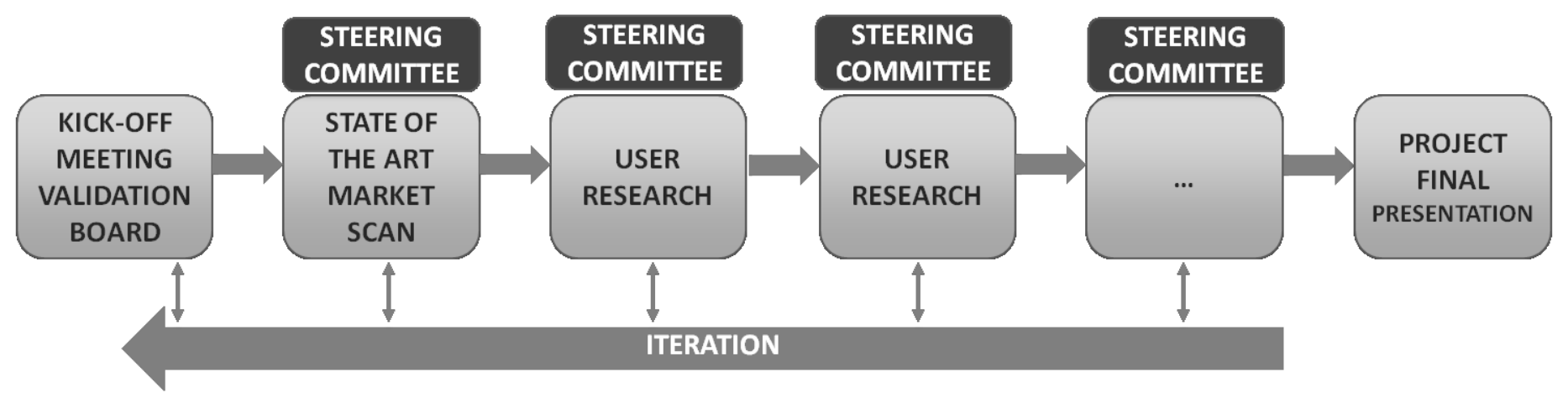

Figure 1. The iMinds Living Labs "pre-business model" innovation project outline 


\section{The Benefits of Integrating Business Model Research within Living Lab Projects}

\section{Olivier Rits, Dimitri Schuurman, and Pieter Ballon}

made from a broad portfolio of user research methodologies including surveys, co-creation sessions, field tests, etc. At the end of the project, a final overview and summary of lessons learned is discussed with the project instigator.

Clearly, no specific business model research was conducted within these "traditional" living lab projects that are in line with the focus of living labs literature on user research. However, because some small and mediumsized enterprises (SMEs) had specific questions regarding the business model, the involvement of business model researchers was included as an "addendum" in some living lab projects. This involvement gradually increased.

Next, we discuss the gradual development of the integration of business model research within living lab projects from project-based business model activities to the $360^{\circ}$ innovation projects.

\section{Phase 1: Project-based business model activities}

Because the need to include proper business model aspects became clear to us gradually, the first business model steps were purely opportunity driven. In other words, when there was a demand for some kind of business model activity, an opportunistic search was launched for external business model expertise. However, these trials were "single shots", where the business model researchers were operating outside of the living lab project (Figure 2).
The MADUF project (Schuurman et al., 2011) was the first large living lab project that had a business modelling research question. One of the desired objectives of the project was to analyze the market as a whole and the corresponding opportunities in order to abstract some policy recommendations. Business modelling efforts were therefore focused on a market-centered view using value network and stakeholder analysis as the main methods (Norman \& Ramirez, 1993; Stabell \& Fjeldstad, 1998).

The next experience with business modelling within a living lab context occurred during an SME project on new business models in the music industry. Again, the living lab researchers did not provide any business model activities in this project, but were working with a customer that was proactively and openly linking the end-user needs and insights with sustainable business model design (Baccarne et al., 2013). This project raised the awareness of the possible strong link and mutual interest between the living lab research and the business model design.

However, as discussed by Baccarne, Schuurman, and Seys (2013), a couple of weaknesses in the approach were identified, the most important being that both user and business model research were too separated from each other along the full innovation track. However, it was concluded that there was scope for increased cross-disciplinary cooperation between user research and business model research in all of the iMinds Living Labs projects.

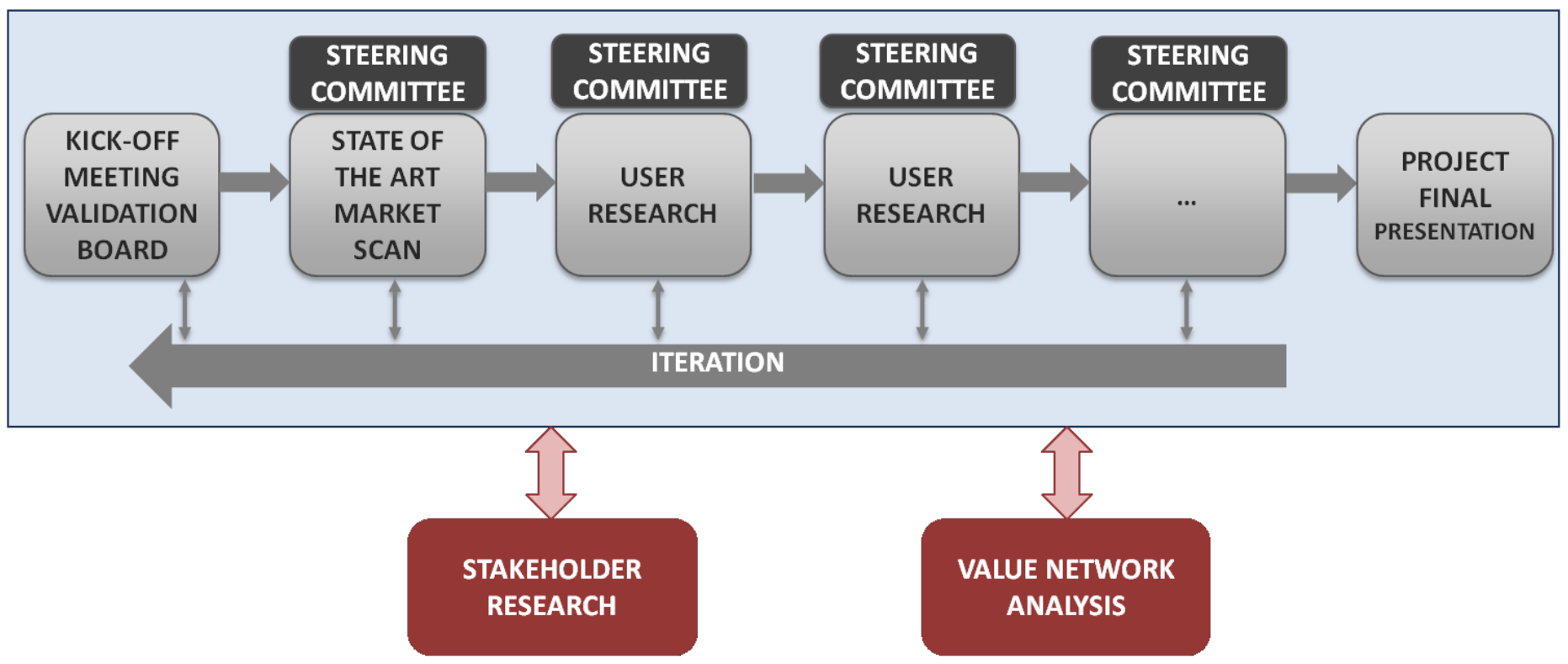

Figure 2. One-shot trials of business model activities within a living lab context through "external" business model expertise 


\title{
The Benefits of Integrating Business Model Research within Living Lab Projects
}

\author{
Olivier Rits, Dimitri Schuurman, and Pieter Ballon
}

Phase 2: Concluding business model workshops

In the next phase, iMinds internalized the business modelling activities within the living lab projects by including the business model researchers right from the start (i.e., during business development and project definition). This process allowed the researchers to capture and understand the business modelling expertise and needs from the instigator side from the very beginning. Thus, the living lab track was redesigned to include the following steps (Figure 3):

1. Kick-off meeting: where the customer explains the innovation concept and is asked to explicate the envisioned business model. However, the formulated research questions remained strongly focused on the end-user aspects given that the researchers were using the validation board from the lean startup approach (Ries, 2011), considering only customer segments, customer needs, and the solution.

2. State of the Art (SotA): consisting of an "environmental scan" via desk research pertaining to the market from both an end-user and business model perspective.

3. A combination of user and stakeholder research steps: dependent upon the specific needs of the innovation instigator, and taking the importance of the business partners into account.

4. A final business model workshop: to link the gathered insights to the business model design and formulating a set of recommendations for the overall strategy related to the innovation.

The benefit of this approach lies in the fact that living lab researchers are forced to generate user research results that are more actionable and practical due to the broader strategic view. The main advantage of planning these business model workshops at the end of the track is that one can discuss strategy based on validated facts and a lot of data. Without the inputs of the living lab research on users and the ecosystem, it would be much harder to counter opposing beliefs. The disadvantage is that, for some projects, the outcome of the business model workshop implied the need to fundamentally change the innovation concept or business model to maximize probability of successful market introduction. The participants found the living lab track to be useful, however, both the researchers and the instigators felt that the business model issues should have been tackled sooner in the process (see Rits et al., 2015). Given the living lab's iterative approach, an earlier examination of business model issues would have allowed the lab to pivot and start exploring, validating, or testing the adapted innovative concept sooner.

Another downside was that stakeholder research happened before the business model workshop, whereas it was deemed necessary to bring up the business model before in order to understand the research questions for that specific stakeholder. These downsides were taken into account and resulted in the development of a third phase.

\section{Phase 3: Steering business model workshops}

In a next phase, the business model workshop was moved forward in the process. The earliest moment when this could take place was deemed to be right after the SotA (Figure 4). By doing rearranging the process, the living lab researchers were able to discuss the business model before any of the user or stakeholder research steps were carried out, while still allowing the business model researchers to get to grips with the particular characteristics of the target market and the prevailing trends.

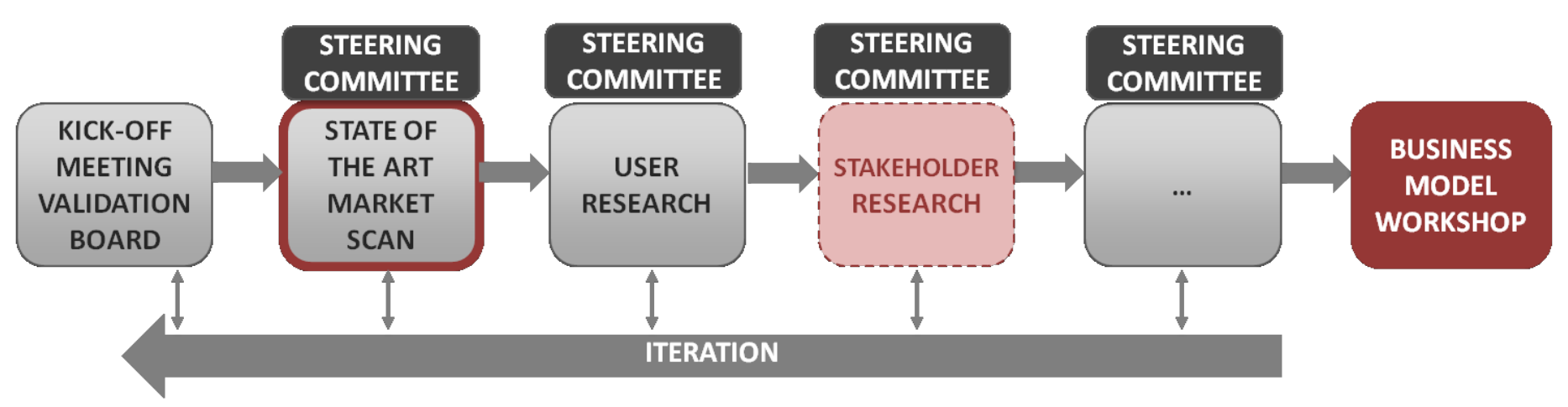

Figure 3. Living lab project outline with concluding business model workshops 


\section{The Benefits of Integrating Business Model Research within Living Lab Projects}

\section{Olivier Rits, Dimitri Schuurman, and Pieter Ballon}

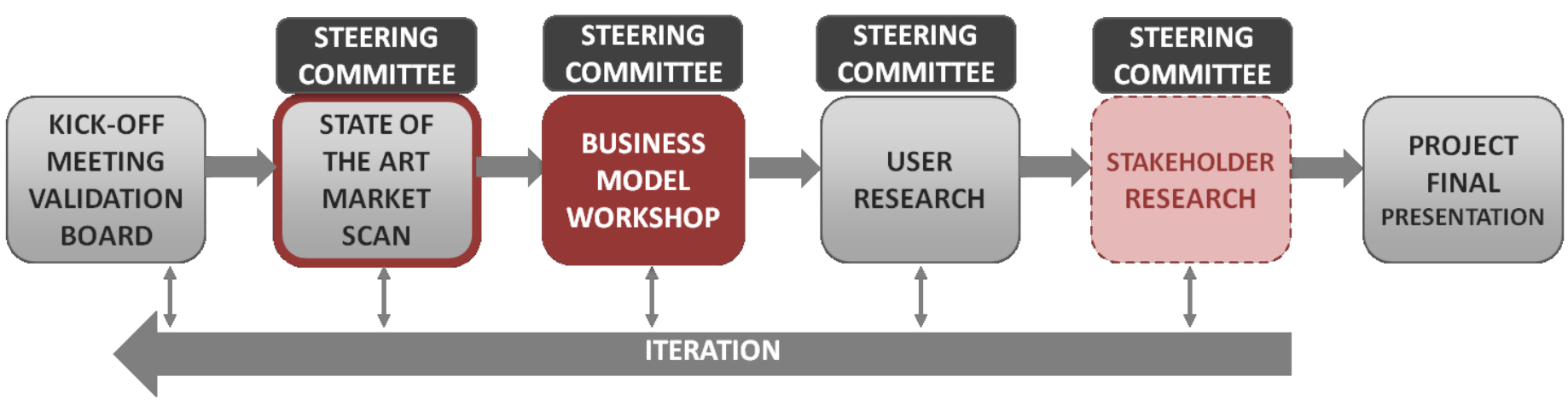

Figure 4. Living lab project outline for steering business model workshops

The advantage of this approach is that living lab researchers were able to detect possible high-impact issues with the business model design at a much earlier stage. Moreover, it made it easier to understand the stakeholder issues and plan for the proper stakeholder research steps, also in view of highly exploratory stakeholder research questions.

However, it rapidly turned out that, triggered by the initial business model workshop, instigators wanted to discuss these results in a broader context and link it to the earlier discussion on the business model. This discussion constrained the organization of the living lab project because it was hard to plan the required business modelling efforts for those unforeseen additional steps.

\section{Phase 4: Full $360^{\circ}$ innovation}

The concluding business model workshop concept clearly showed that a living lab track is able to provide much more information and insights besides the obvious user needs and usage of the innovation itself. Living lab user research is able to uncover the relevant usage context (e.g., time, location, trigger, community) for all the different phases of the customer-buying experience journey (Chan \& Mauborgne, 2005). This approach helps the instigator to fine-tune the different value aspects of the full business model with links to marketing, distribution, ecosystem, pricing, etc.

From an assessment point of view, the living lab researchers saw that the required fundamental adaptation for some of the projects was mainly driven by the combination of a lack of resources and a misalignment with the current strategy. Resources and strategy are strongly linked, because strategy will define which resources are required, and resources will define (to some degree) which strategy can be pursued. However, resources are limited - particularly for SMEs - and it is important to carefully plan which resources should be dedicated to which activities. Resources are required not only for value creation itself, but also for value delivery, value capture, and the value consumption parts of the business model. This discovery led to the understanding that, in highly iterative tracks (as typically in a living lab context), the resource view and strategy view (i.e., the business model view) are required at all times to ensure the instigator will be able to sustainably profit from the innovation (Teece, 1986).

However, the benefits do not only flow from living lab to business model, but also the other way around. The different components of any business model framework are strongly interlinked with the end user, which is a central and key component in most business model frameworks. When shaping the user research, the context of the user is important. Taking the full business model view into account helps living lab researchers to be more specific, allowing for more valuable and relevant feedback from users and stakeholders.

With the three lessons described above in mind and looking for a way to alleviate the operational strain from the steering business model concept, iMinds Living Lab redesigned the innovation track by embedding user, stakeholder and business model research in every single step and from the very start (Figure 5), enabling $360^{\circ}$ innovation. In practice, the business model workshops are now embedded as part of the steering committees, during which the user and stakeholder aspect were already being discussed.

\section{Discussion and Conclusion}

A lot of the academic literature on business models still struggles with the exact definition and outline of the concept and deals with meta-analyses of definitions and single case studies illustrating best and worst practices in order to abstract the underlying dynamics, char- 


\section{The Benefits of Integrating Business Model Research within Living Lab Projects}

\section{Olivier Rits, Dimitri Schuurman, and Pieter Ballon}

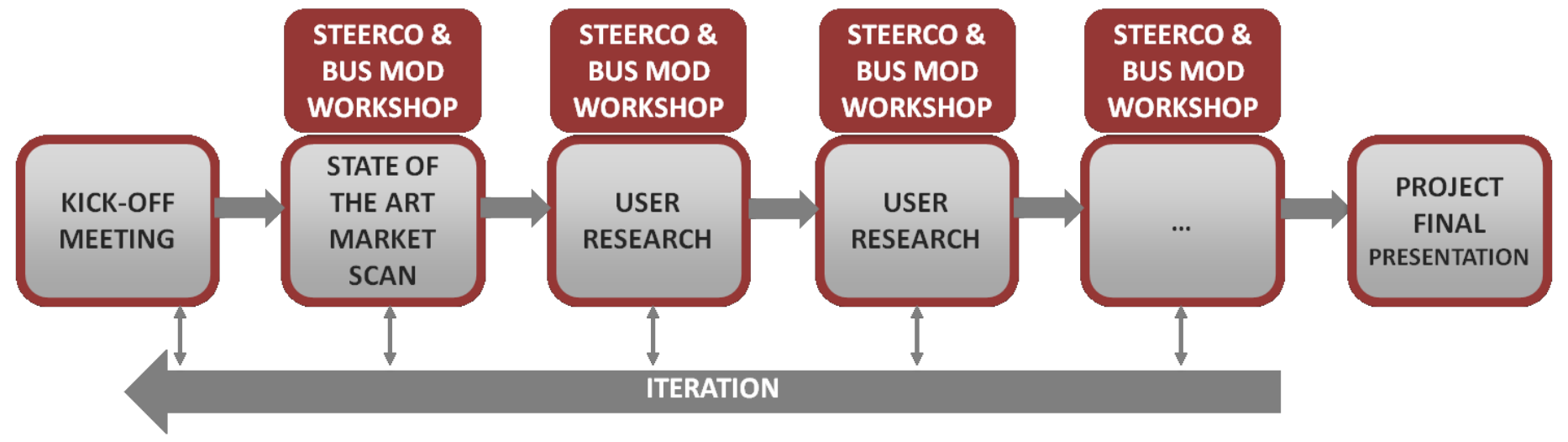

Figure 5. Outline for a living lab project labeled as $360^{\circ}$ innovation

acteristics, and constructs that define a business model. The more practically oriented literature on business models offers practical frameworks and tools that consist of different (supposedly) critical elements in order to allow managers to log these aspects. Although it is stated that a business model consists of dynamic elements that determine the eventual outcome of a business model, the field lacks concrete tools and approaches to investigate these dynamic elements and to test the different elements of the business model in practice. With this article, we introduced the idea of integrating business model research with living lab research, because living lab researchers actively involve end users and stakeholders in the innovation development process by means of multiple research methods and including real-life experimentation and validation. This experimental approach allows business model researchers to consider the business implications of the different phases of any business by means of concrete research data that enables to capture the "dynamic aspects" of the business model: from value creation, to value distribution, to value consumption. and finally, to value capture.

Within this article, we have demonstrated how the practical integration of living lab research with business model research has evolved within the iMinds Living Labs organization in four phases. Starting from the innovation track design to the forth and last design - the $360^{\circ}$ innovation track - we have discussed the mutual benefits of strongly linking and embedding user research and business model research into the same innovation track. Contrary to the statement by Katzy (2012), that business model insights from living lab tracks would be difficult to sell, the experience gained by iMinds Living Labs has turned this aspect (business modelling services) into one of the key services, next to that of user research, panel management, prototyping, and living lab methodology.

Moreover, the combined approach has challenged the living lab researchers to adapt and improve the design and implementation of a living lab innovation track. This ability to design and manage efficient integrated innovation tracks is drawing a lot of interest from partnering institutions and stakeholders. As a result, a growing part of the activities of the iMinds Living Lab researchers is to educate and train other organizations in designing and managing highly iterative innovation tracks with combined user and business model research. To support our own integrated innovation tracks and to educate partner organizations, the iMinds Living Lab team is working on a dedicated and customized toolbox - the Living Lab Assumption and VAlidation (LLAVA) matrix - as part of next steps and further research: for a first version of this matrix, see Rits, Schuurman, an Ballon (2015). The LLAVA matrix logs and explicates the different elements and characteristics of the business model (the framework level), as a dynamic tool to point out assumptions that need to be researched in subsequent stages of the living lab project and as a starting point of discussion for the innovation instigator to decide upon the next steps to be taken in terms of the innovation development (the process level), and it enables both the project instigators and the involved researchers to dynamically assess and test the critical aspects of the business model: alignment with company goals, internal consistency, and robustness (the analysis level). This toolbox is currently being tested in all iMinds Living Labs projects, so future research will be able to analyze the concrete outcomes and impacts of our approach. 


\section{The Benefits of Integrating Business Model Research within Living Lab Projects}

\section{Olivier Rits, Dimitri Schuurman, and Pieter Ballon}

\section{About the Authors}

Olivier Rits graduated as an Engineer in Applied Physics from Ghent University in Belgium. Olivier joined Alcatel-Lucent as a business developer where he worked on the go2market strategy for innovative solutions, both on networking and applications. He joined iMinds in 2013, focusing on the intersection between technology, business, and innovation. Olivier leads the business model practice at the iMinds Living Labs, where he is responsible for the methodologies used and providing business support to startups, SMEs, and larger organizations.

Dimitri Schuurman holds a $\mathrm{PhD}$ (2015) and Master's degree in Communication Sciences (2003) from Ghent University in Belgium. He joined the research group iMinds - MICT - Ghent University in 2005 and started working at iMinds Living Labs in 2009. Together with his iMinds colleagues, Dimitri developed a specific living lab offering targeted at startups and SMEs, in which he has managed over 50 innovation projects. As a senior researcher, Dimitri is currently responsible for the methodology and academic valorization of living lab projects. He also coordinates a dynamic team of living lab researchers from iMinds - MICT - Ghent University. His main interests and research topics are situated in the domains of open innovation, user innovation, and innovation management. In early 2015, he finished his $\mathrm{PhD}$ entitled Bridging the Gap between Open and User Innovation? Exploring the Value of Living Labs as a Means to Structure User Contribution and Manage Distributed Innovation.

Pieter Ballon is the Director of iMinds Living Labs, the International Secretary of the European Network of Living Labs, and a Professor at Vrije Universiteit Brussel in Belgium. He specializes in business modelling, open innovation, and the mobile telecommunications industry. Formerly, he was senior consultant and team leader at TNO. In 2006-2007, he was the coordinator of the cross issue on business models of the Wireless World Initiative (WWI), which united five integrated projects in the European Union's 6th Framework Programme. Pieter holds a PhD in Communication Sciences from Vrije Universiteit Brussel and a MA in Modern History from Katholieke Universiteit Leuven.

\section{Further Reading}

Outside the scientific literature, we recommend two handbooks that bundle a set of best practices for living lab research:

1. The KC3 Business Model from the European Network of Living Labs (ENoLL) discusses the need for a business model for cross-border living lab collaboration, positioning it in the first group of living lab literature. tinyurl.com/zej2nwp

2. The Living Lab Methodology Handbook from the Botnia Living Lab mentions business modelling as part of the service offering, but only at a high level, positioning it in the third group of living lab literature. tinyurl.com/z362nd4

\section{Acknowledgements}

An earlier version of this paper was presented at the XXVI International Society for Professional Innovation Management (ISPIM) Conference - Shaping the Frontiers of Innovation Management, Budapest, Hungary, 14-17 June, 2015.

\section{References}

Agerskov, M. L., \& Hoj, J. C. L., 2013. Lessons Learned from the Danish EV Living Lab. EVS 27 International Battery, Hybrid and Fuel Cell Electric Vehicle Symposium. World Electric Vehicle Journal, 6: 0969.

Al-Debei, M. M., \& Avison, D. 2010. Developing a Unified Framework of the Business Model Concept. European Journal of Information Systems, 19(3): 359-376.

http://dx.doi.org/10.1057/ejis.2010.21

Baccarne, B., Schuurman, D., \& Seys, C. 2013. Living Labs as a Navigation System for Innovative Business Models in the Music Industry. Paper presented at the XXIV ISPIM Conference, Helsinki, Finland, June 16-19, 2013.

Ballon, P. 2007. Business Modelling Revisited: The Configuration of Control and Value. info, 5(9): 6-19. http://dx.doi.org/10.1108/14636690710816417

Breuer, H., \& Mahdjour, S. 2012. Lean Venturing: Entrepreneurial Learning to Model and Grow New Business. Paper presented at the 5th ISPIM Innovation Symposium, Seoul, Korea, Dec 9-12, 2012.

Casadesus-Masanell, R., \& Ricart, J. E. 2010. From Strategy to Business Models and onto Tactics. Long Range Planning, 43(2): 195-215.

http://dx.doi.org/10.1016/j.lrp.2010.01.004 


\section{The Benefits of Integrating Business Model Research within Living Lab Projects}

\section{Olivier Rits, Dimitri Schuurman, and Pieter Ballon}

Chan, K. W., \& Mauborgne, R. 2005. Blue Ocean Strategy: How to Create Uncontested Market Space and Make Competition Irrelevant. Boston, MA: Harvard Business Press.

Coorevits, L., \& Schuurman, D. 2014. Hypothesis Driven Innovation: Lean, Live and Validate. Paper presented at the XXV ISPIM Innovation Conference, Dublin, Ireland, June 8-10, 2014.

García-Guzmán, J., del Carpio, A. F., de Amescua, A., \& Velasco, M. 2013. A Process Reference Model for Managing Living Labs for ICT Innovation: A Proposal Based on ISO/IEC 15504. Computer Standards \& Interfaces, 36(1): 33-41. http://dx.doi.org/10.1016/j.csi.2013.07.004

Giesen, E., Berman, J., Bell, R., \& Blitz, A. 2007. Three Ways to Successfully Innovate Your Business Model. Strategy \& Leadership, 35(6): 27-33 http://dx.doi.org/10.1108/10878570710833732

Grezes, V., Fulgencio, H., \& Perruchoud, A. 2013. Embedding Business Model for Sustainable Collaborative Innovation in African Living Labs. Paper presented at the IEEE IST-Africa Conference \& Exhibition, Nairobi, Kenya, May 15-17.

Katzy, B. 2012. Designing Viable Business Models for Living Labs. Technology Innovation Management Review, 2(9): 19-24. http://timreview.ca/article/604

Magretta, J. 2002. Why Business Models Matter. Harvard Business Review: 80(5): 86-92.

Mulvenna, M., Bergvall-Kåreborn, B., Wallace, J., Galbraith, B., \& Martin, S. 2010. Living Labs as Engagement Models for Innovation. Paper presented at eChallenges, Warsaw, Poland, October 27-29, 2010.

Nenonen, S., \& Storbacka, K. 2010. Business Model Design: Conceptualizing Networked Co-Creation. International Journal on Quality and Service Sciences, 2(1): 43-59. http://dx.doi.org/10.1108/17566691011026595

Niitamo, V.-P., Kulkki, S., Eriksson, M., \& Hribernik, K. A. 2006. Stateof-the-Art and Good Practice in the Field of Living Labs. In Proceedings of the 12th International Conference on Concurrent Enterprising, ICE2006: 341-348.

Nikolov, R., \& Antonova, A. 2012. Developing Experiential Living Lab as Platforms for Embedded Innovation. Paper presented at the 18th International Conference on Engineering, Technology and Innovation (ICE) / IEEE, Munich, Germany, June 18-20, 2012. http://dx.doi.org/10.1109/ICE.2012.6297635

Normann, R., \& Ramirez, R. 1993. From Value Chain to Value Constellation: Designing Interactive Strategy. Harvard Business Review, 71; 65-77.

Osterwalder, A., Pigneur, Y., \& Clark, T. 2010. Business Model Generation. Hoboken, NJ: Wiley.

Pitse-Boshomane, M. M., Marais, M. A., Morris, C., Roux, K., van Rensburg, R., Herselman, M., Makan, A., \& Mulder, I. 2008. Catalysing Innovation: The Promise of the Living Lab Approach in South Africa. Paper presented at the Prato CIRN 2008 Community Informatics Conference, Prato, Italy, November 9-11, 2008.
Ries, E. 2011. The Lean Startup. New York: Crown Business.

Rits, O., Schuurman, D., \& Ballon, P. 2015. Exploring the Benefits of Combining Business Modelling with Living Labs. Paper presented at the XXVI ISPIM Conference: Shaping the Frontiers of Innovation Management, Budapest, Hungary, 14-17 June, 2015.

Shafer, S. M., Smith, H. J., \& Linder, J. C. 2005. The Power of Business Models. Business Horizons, 48(3): 199-207. http://dx.doi.org/10.1016/j.bushor.2004.10.014

Schaffers, H., Merz, C., \& Guzman, J. G. 2009. Living Labs as Instruments for Business and Social Innovation in Rural Areas. In Proceedings of the 2009 ICE Conference, Leiden, The Netherlands, June 22-24, 2009.

Schuurman, D., De Moor, K., De Marez, L., \& Evens, T. 2011. A Living Lab Research Approach for Mobile TV. Telematics and Informatics, 28(4): 271-282.

http://dx.doi.org/10.1016/j.tele.2010.11.004

Schuurman, D., Marez, L. D., \& Ballon, P. 2013. Open Innovation Processes in Living Lab Innovation Systems: Insights from the LeYLab. Technology Innovation Management Review, 3(11): 28-36. http://timreview.ca/article/743

Schuurman, D. 2015. Bridging the Gap between Open and User Innovation? Exploring the Value of Living Labs as a Means to Structure User Contribution and Manage Distributed Innovation. Doctoral Dissertation. Ghent University. Faculty of Political and Social Sciences; Vrije Universiteit Brussel. Faculty of Economic and Social Sciences, Ghent; Brussels, Belgium.

Svensson, J., \& Eriksson, C. I. 2009. Open Innovation in Small Enterprises - A Living Lab Approach. Paper presented at the XX ISPIM Conference Vienna, Austria, June 21-24, 2009.

Teece, D. J. 1986. Profiting from Technological Innovation: Implications for Integration, Collaboration, Licensing and Public Policy. Research Policy, 15(6): 285-305. http://dx.doi.org/10.1016/0048-7333(86)90027-2

Teece, D. J. 2010. Business Models, Business Strategy and Innovation. Long Range Planning, 43(2-3): 172-194. http://dx.doi.org/10.1016/j.lrp.2009.07.003

Stabell, C., \& Fjeldstad, O. 1998, Configuring Value for Competitive Advantage: On Chains, Shops, and Networks. Strategic Management Journal, 19: 413-437.

Voelpel, S., Leibold, M., Tekie, E,. \& von Krogh, G. 2005. Escaping the Red Queen Effect in Competitive Strategy: Sense-Testing Business Models. European Management Journal, 23(1): 37-49. http://dx.doi.org/10.1016/j.emj.2004.12.008

Zott, C., \& Amit, R. 2010. Business Model Design: An Activity System Perspective. Long Range Planning, 43(2): 216-226. http://dx.doi.org/10.1016/j.lrp.2009.07.004 